\title{
Triatoma jurbergi sp. n. do Norte do Estado do Mato Grosso, Brasil (Hemiptera, Reduviidae, Triatominae) com uma Atualização das Sinonímias e outros Táxons
}

\author{
Rodolfo U Carcavallo/ ${ }^{+}$, Cleber Galvão, Herman Lent*
}

Laboratório Nacional e Internacional de Referência em Taxonomia de Triatomíneos, Departamento de Entomologia, Instituto Oswaldo Cruz, Av. Brasil 4365, 21045-900 Rio de Janeiro, RJ, Brasil *Centro de Ciências Biológicas,

Universidade Santa Úrsula, Rua Jornalista Orlando Dantas 59, 22231-010 Rio de Janeiro, RJ, Brasil

Triatoma jurbergi sp. n. from the State of Mato Grosso, Brazil (Hemiptera, Reduviidae, Triatominae) with an Updated List of Synonyms and other Taxa - Triatoma jurbergi $n$. $s p$. is described based on nine specimens of both sexes deposited in the Rodolfo Carcavallo Collection in the Oswaldo Cruz. Institute Entomological Collection. The new species can be separated from the closely related Triatoma guazu Lent \& Wygodzinsky, 1979 by several characters. The most important are longer anteocular region; thin and pointed juga; the shape of the eyes without concavity in the posterior edge; much longer second rostral segment, passing the posterior edge of eye; the absence of a ventral longitudinal depression on the abdomen; the general color redish, brown and orange and the male genitalia, mainly in the vesica lightly chitinized and smaller, the phallosome with apical projection and the pointed apex of the endosome process.

Key words: Triatominae - Chagas' disease - Triatoma jurbergi sp. n.

A captura de espécimes de Triatoma guazu Lent \& Wygodzinsky, 1979 em domicílios no Brasil foi realizada pela primeira vez em 1994, por técnicos da Fundação Nacional de Saúde (FNS), na localidade de Barra do Garça, Mato Grosso. Isto permitiu que esta espécie, descrita com base em um único espécime fêmea, proveniente do Paraguai, pudesse ter sua diagnose ampliada através da descrição do alótipo macho, do estudo da genitália externa masculina realizada por Lent et al. (1996) e pelo estudo morfológico através da microscopia eletrônica de varredura (GalíndezGirón et al. 1997b). Além disso, foi possível iniciar uma colônia desta espécie no insetário do Laboratório Nacional e Internacional de Referência em Taxonomia de Triatomíneos, o que permitirá a ampliação do conhecimento sobre sua bionomia e morfologia das ninfas. Desde 1994, pesquisadores da FNS vêm avaliando a importância desta espécie na epidemiologia da doença de Chagas e resultados preliminares foram publicados recentemente (Valente et al. 1997).

Com auxílio do CNPq, Convênio FNS/Fiocruz no 123 / 97, European Commission contract IC1B-CT96-0042/ ECLAT.

${ }^{+}$Autor de contato. Fax: +55-21-290.9339. E-mail: carcaval@gene.dbbm.fiocruz.br Recebido em 6 janeiro de 1998 Aceito em 8 de abril de 1998
Em um novo lote de espécimes enviados pela FNS para identificação, provenientes da localidade de Rondonópolis, Mato Grosso, a cerca de $280 \mathrm{~km}$ de Barra do Garça, a presença de adultos e ninfas assemelhados a T. guazu foi observada. Esses espécimes apresentavam um colorido avermelhado em todos os estádios, comparável ao de Triatoma rubrovaria (Blanchard, 1843), porém deste se distinguindo pela ausência da coloração negra. Esta caraterística cromática foi constante em todos os exemplares nascidos e mantidos na atual colônia.

Após a análise comparativa das características anatômicas de ambos os sexos e da observação da descendência em laboratório das duas amostras, concluímos que são espécies distintas, sendo designada a que aqui se descreve como Triatoma jurbergi sp. n. (Figs. 1, 2, 3).

Esta é a 112 espécie de triatomíneo nas Américas a ser descrita, pois desde a obra de Lent e Wygodzinsky (1979) que agrupou num mesmo trabalho a descrição pormenorizada de cada espécie, dados de sua distribuição geográfica e habitats, foram descritas outras dez espécies (Jurberg \& Galvão 1997). Algumas espécies foram sinonimizadas e outras sofreram mudanças nas posições sistemáticas.

\section{Sinonímias}

Triatoma gallardoi Carpintero, 1986 é sinônimo de Triatoma patagonica Del Ponte, 1929 (Carcavallo \& Martínez 1987).

Triatoma funerea Carpintero \& Leguizamón, 
1994 de Triatoma melanosoma Martínez, Olmedo \& Carcavallo, 1987 (Lent et al. 1995).

Psammolestes salazari, Aldana, Lizano, Ramón \& Valderrama, 1996 de Psammolestes arthuri (Pinto 1926) (Lent 1997).

Panstrongylus turpiali Valderrama, Lizano, Cabello \& Valera, 1996 de Panstrongylus chinai (Del Ponte, 1929) (Lent 1997).

\section{Mudanças de gênero}

Triatoma spinolai Porter, 1934 para Mepraia spinolai, pela revalidação do gênero Mepraia Mazza, Gajardo \& Jorg, 1940 (Lent et al. 1994).

Triatoma matsunoi Fernandez-Loayza, 1989 para Hermanlentia matsunoi pela descrição de um novo gênero (Jurberg \& Galvão 1997).

\section{Nomen nudum}

Rhodnius jacundaensis Serra, Serra \& Atzingen, 1980. Segundo o Art. 9o do Código Internacional de Nomenclatura Zoológica (Serra et al. 1980).

\section{Triatoma jurbergi $\mathrm{sp} . \mathrm{n}$.}

Descrição - Comprimento total dos machos: 25 a $26 \mathrm{~mm}$, das fêmeas: 27 a $28 \mathrm{~mm}$; largura do pronoto dos machos: $6 \mathrm{~mm}$, das fêmeas: $7 \mathrm{~mm}$; largura do abdômen dos machos ao nível do 5으 segmento: $9 \mathrm{~mm}$, das fêmeas: $11 \mathrm{~mm}$ (Figs.1, 2, 3).

Cor geral, marrom avermelhado. A coloração é alaranjada em quase todo o cório e nas manchas

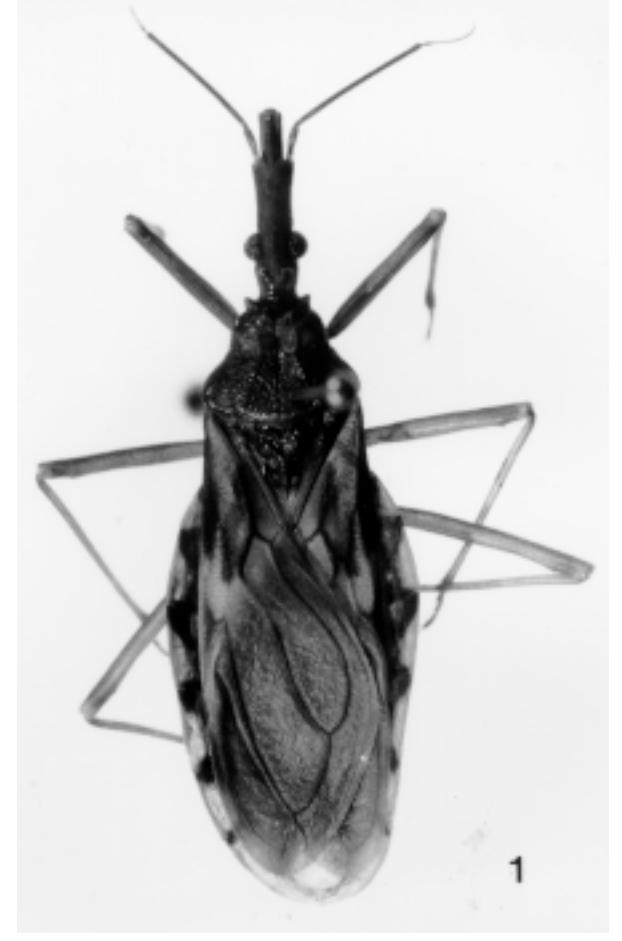

Fig. 1: Triatoma jurbergi sp. n., macho, vista dorsal.

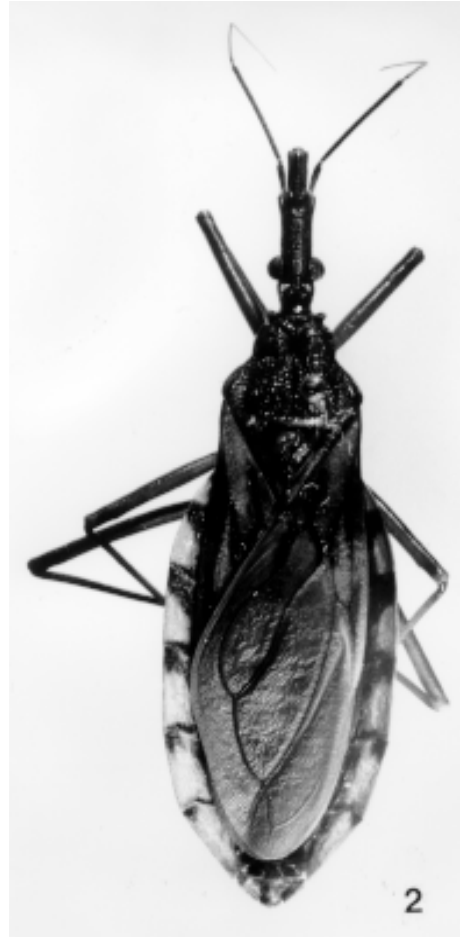

Fig. 2: Triatoma jurbergi sp. n., fêmea, vista dorsal.

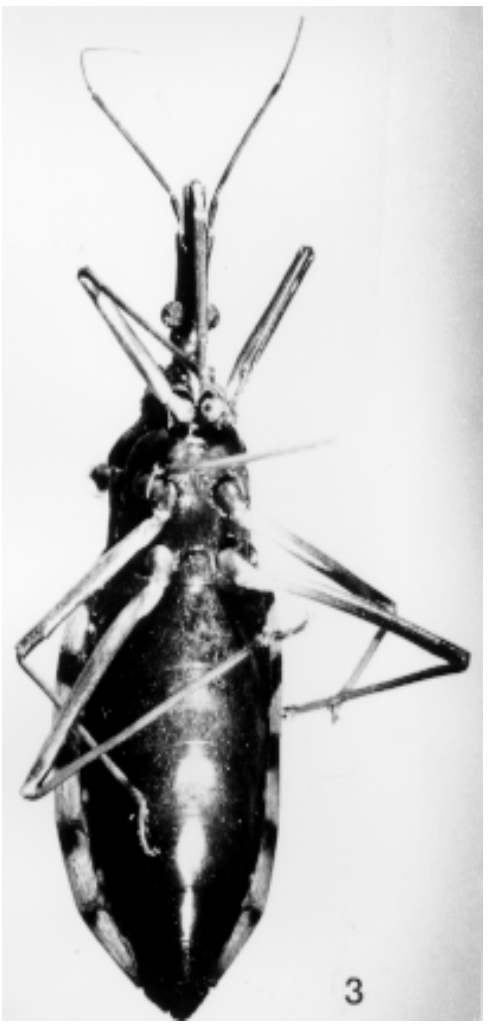

Fig. 3: Triatoma jurbergi sp. n., fêmea, vista ventral. 
semi-circulares do conexivo nos segmentos dorsais e nos $3 / 4$ dos segmentos ventrais. O VII urotergito é totalmente alaranjado. Áreas de coloração marrom escuro: clavo, veias, especialmente $\mathrm{Cu}, \mathrm{M}$ e $\mathrm{R}+\mathrm{M}$, manchas triangulares no $1 / 4$ anterior dos segmentos conexivais e uma linha estreita na região posterior de cada segmento. São castanho-píceo o abdômen visto ventralmente e o segundo segmento antenal.

Cabeça castanho vermelho com tegumento suavemente granuloso, 2,8 vezes mais longa que larga ao nível dos olhos e muito mais longa que o pronoto (relação 1:0,58). Região ante-ocular seis ou mais vezes mais longa que a pós-ocular (relação 1:0,16). Região pós-ocular fortemente convexa com os lados suavemente arredondados. Clípeo não alcançando o nível das genas, ficando com uma apreciável diferença, com a metade posterior moderadamente alargada. Genas ligeiramente aguçadas apicalmente, jugos estreitos com aspecto laminar afilados no ápice. Olhos medianos, quando vistos lateralmente, ultrapassam nitidamente o bordo inferior da cabeça. Relação entre a largura de um olho e a região inter-ocular ou sinlipsis $1: 1,16$. Ocelos pequenos, separados dos olhos por quase duas vezes seu comprimento. Tubérculos anteníferos situados bem à frente da metade da região pré-ocular; $1^{\mathrm{o}}$ segmento antenal muito mais curto que o nível apical das genas e do clípeo. Relação dos segmentos antenais 1: 4.5: 3.5: 3. Rostro com o $1^{\mathrm{o}}$ segmento curto, $2^{\mathrm{o}}$ segmento ultrapassando o bordo posterior dos olhos chegando quase ao nível dos ocelos, $3^{\circ}$ segmento do mesmo comprimento do primeiro chegando ao terço anterior do sulco estridulatório. Relação dos segmentos rostrais: 1: 3.2: 1 (Fig. 4).

Pronoto castanho avermelhado. Lobo anterior com escultura bem marcada, tubérculos discais pouco aparentes. Ângulos ântero-laterais do colar muito divergentes, cilindrocônicos e grandes. Lobo posterior granuloso com a carena intermediana chegando quase ao bordo posterior do pronoto, carenas laterais bem marcadas e de superfície rugosa. Ângulos humerais arredondados, salientes voltados para cima. Escutelo avermelhado, muito rugoso com a depressão central profunda, variável e grande. Processo do escutelo aguçado, quase do mesmo comprimento do corpo, delgado e arredondado no ápice (Figs. 1, 2).

Hemélitros não alcançando o ápice do VIII tergito. Cório laranja, membrana cinza, clavo e veias marron-escuro.

Patas inteiramente castanho-avermelhadas com exceção dos trocânteres que são amarelados, todos os fêmures possuem pequenos tubérculos. Abdômen com os urotergitos expostos, ventralmente convexo e de superfície brilhante, microestriado, com micropilosidade abundante,
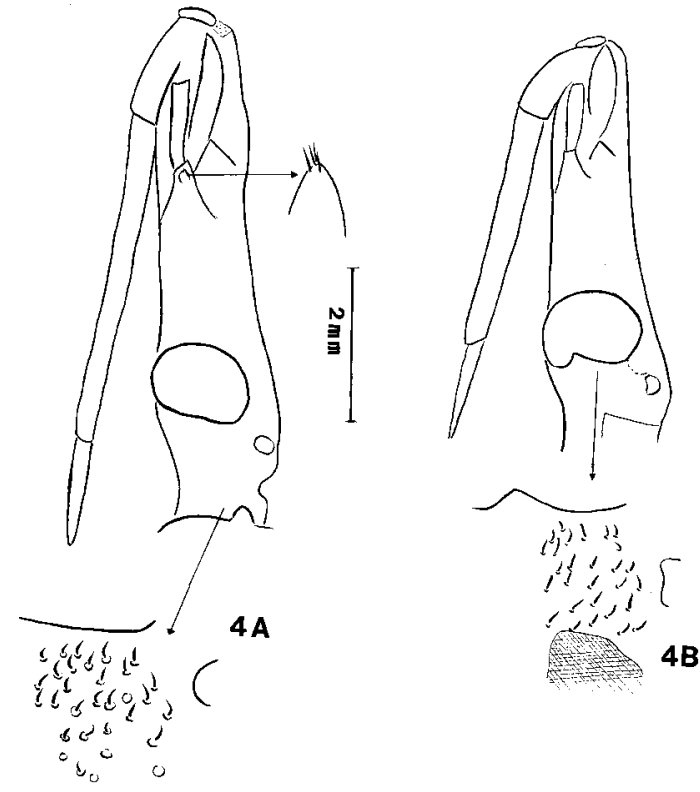

Fig. 4 - A: Triatoma jurbergi sp. n., cabeça, vista lateral; B: Triatoma guazu Lent \& Wygodzinsky, 1979, cabeça, vista lateral.

espiráculos situados na linha da sutura conexival. Conexivo castanho escuro, com uma mancha subtriangular alaranjada em cada segmento que chega ventralmente até a sutura conexival.

Falo composto de um aparelho articular (Apb) e um edeago (Ae) de proporcões iguais. Em repouso o falo fica dobrado com o aparelho articular dorsalmente situado e o edeago com o ápice voltado em direção à cabeça. $\mathrm{O}$ falo fica localizado dentro do $9^{\mathrm{O}}$ segmento que alberga $1+1$ parâmeros (Pa) e o processo mediano do pigóforo (PrP) (Figs. 5-10). Parâmeros iguais, cilíndricos, curvados com o ápice dilatado em forma de aba com uma área terminal como se fosse um espinho, metade apical da face externa com pêlos longos entremeados de pêlos curtos (Figs. 8, 9). Processo mediano do pigóforo (PrP) bastante quitinizado situado no bordo inferior da abertura genital com formato trianguliforme (Fig. 10). Edeago globoso, complexo constituído de estruturas quitinizadas e membranosas, destacando-se o falosoma $(\mathrm{Ph})$, o suporte do falosoma (Sph), a vesica (V), endosoma (En) e a conjuntiva (Cj) (Figs. 5, 6, 7). Falosoma $(\mathrm{Ph})$ constituído por uma placa laminar, ovóide, com uma projeção apical (Fig. 6). Suporte do falosoma (SPh) localizado internamente e constituído por uma estrutura de base cilíndrica e a parte apical de dois braços paralelos unidos por uma área membranosa no ápice (Fig. 6). Processo do endosoma (PrEn) constituído por 1+1 estruturas medianamente quitinizadas situadas nas laterais do edeago, estriadas longitudinalmente, ápice 
acuminado recoberto de pequenos espinhos voltados para baixo (Figs. 7, 11). Vesica (V), estrutura ímpar, fracamente quitinizada presa ao endosoma e localizada no ápice do edeago (Fig. 12). Conjuntiva $(\mathrm{Cj})$ membrana elástica, estriada longitudinalmente que envolve o endosoma (Figs. 5,7). Aparelho articular (Apb) com a forma de um Y invertido é constituído pela placa basal (Plb), pela ponte basal (PB), extensão mediana da placa basal (Eplb) e processo do gonoporo (PrG), funciona como estrutura de articulação para o edeago se exteriorizar no momento da cópula (Figs. $5,6)$. Placa basal (Plb) constitue os braços do Y invertido e se prende dentro do pigóforo através de três estruturas denominadas cada uma de processo capitato. A extensão mediana da placa basal é o braço ímpar do aparelho articular, constituído de uma placa retangular cujo ápice é levemente fendido mostrando o bordo superior fendido e o inferior soldado à placa basal (Fig. 5).
Processo do gonoporo (PrG) constituído por uma estrutura cilíndrica oca localizada na área interna do aparelho articular (Fig. 6). Ponte basal (PB) cilíndrica fortemente quitinizada, une dois pontos da placa basal (Fig. 5) (Jurberg et al. 1997).

Material examinado - Triatoma jurbergi sp. n.: macho, holótipo, Brasil, Mato Grosso, coletado en Rondonópolis (IX-1997), № 2903 da Coleção Rodolfo Carcavallo do Instituto Oswaldo Cruz; fêmea alótipo, mesma procedência e data, №s 2904 da Coleção; três fêmeas parátipos, №s 2905, 2906 e 2909, e dois machos parátipos №s 2907 e 2908, todos da mesma procedência e data.

Diagnose: a nova espécie apresenta semelhança morfológica com T. guazu da qual se diferencia entre outras características pelo comprimento da região anteocular em vista dorsal nitidamente maior que o comprimento de três olhos, enquanto em $T$. guazu essa relação é de apenas duas vezes e meia, ou menos, o que confere à cabeça

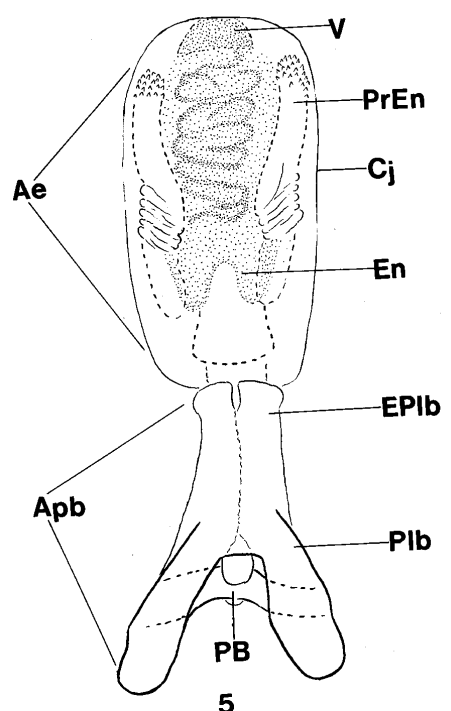

5

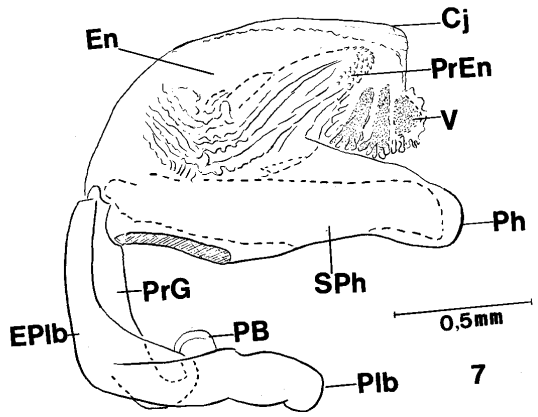

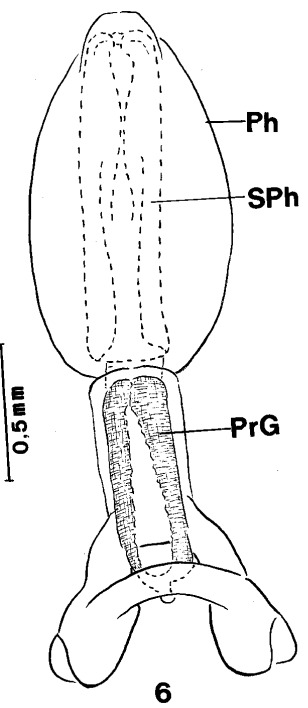

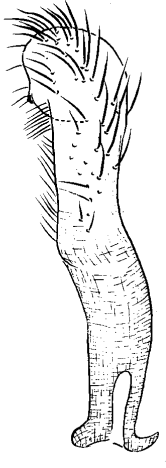

8
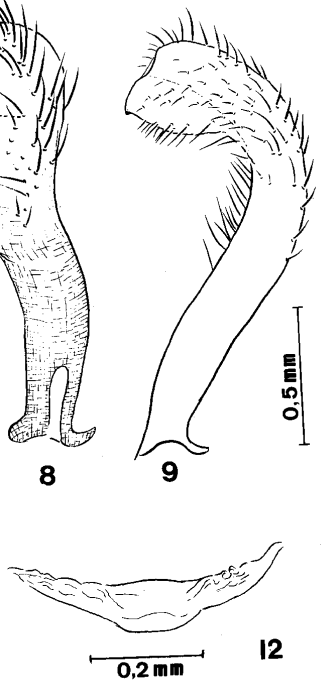

12

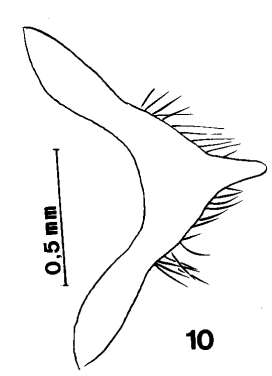

11

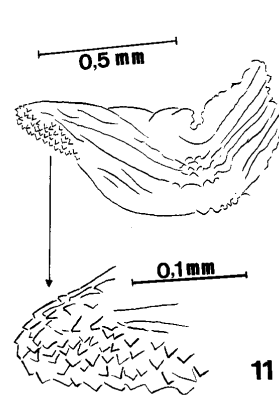

Triatoma jurbergi sp. n. Figs. 5, 6, 7: falo, vista dorsal, ventral e lateral respectivamente (Ae: edeago, Apb: aparelho articular, Cj: conjuntiva, En: endosoma, EPlb: extensão mediana da placa basal, PB: ponte basal, Ph: falosoma, Plb: placa basal, PrEn: processo do endosoma, PrG: processo do gonoporo, SPh: suporte do falosoma, V: vesica). Figs. 8, 9: parâmero em vista lateral e dorsal, respectivamente . Fig. 10: processo mediano do pigóforo. Fig. 11: processo do endosoma. Fig. 12: vesica. 
TABELA

Caracteres morfológicos diferenciais entre Triatoma jurbergi sp. n. e Triatoma guazu Lent \& Wygodzinsky, 1979

\begin{tabular}{lll}
\hline & Triatoma jurbergi sp. n. & Triatoma guazu \\
\hline Cabeça & Mais longa (Fig. 4A) $1.5>$ que pronoto & $\begin{array}{l}\text { Mais curta (Fig. 4B) } 1.2>\text { que } \\
\text { pronoto }\end{array}$
\end{tabular}

Região ante-ocular

Bordo posterior do olho

Rostro

Pronoto e escutelo

Abdômen em vista ventral

Vesica

Falosoma

Processo do endosoma (Fig. 11) Ápice acuminado com numerosos dentículos (Fig. 3)
Mais longa (Fig. 4A) 6 ou mais vezes maior que a pós-ocular

Liso (Fig. 4A)

2o segmento ultrapassando o nível dos olhos (Fig. 4A)

1+1 tubérculos discais (Figs.1, 2).

Ângulos anterolaterais proeminentes cilindrocônicos. Processo escutelar quase igual ao corpo
Mais curta (Fig. 4B) 4 ou menos vezes maior que a pós-ocular

Com reêntrancias (Fig. 4B)

$2^{2}$ segmento atingindo a região mediana dos olhos (Fig. 4B)

Tubérculos discais ausentes. Ângulos anterolaterais muito pequenos subcônicos. Processo escutelar com a metade do comprimento do corpo

Não achatado, carenado longitudinalmente Levemente achatado longitudinalmente

Menor, fracamente quitinizada (Fig. 12)

Maior, fortemente quitinizada (Lent et al. 1996)

Ovóide sem projeção apical (Lent et al. 1996)

Ápice arredondado com numeroso dentículos (Lent et al. 1996) um aspecto mais robusto e os olhos são maiores; jugos mais estreitos e aguçados enquanto que em T. guazu, segundo Lent e Wygodzinsky (1979) são "narrowly rounded apically", caracter não muito marcado, mas constante, que foi confirmado nos espécimes criados no insetário; pelas proporções das diversas áreas da região pós-ocular; pela escultura da região óculo-ocelar; pela forma do olho com uma depressão posterior acentuada em T. guazu e ausente na nova espécie; pelo tamanho do $2 \underline{\mathrm{o}}$ segmento do rostro que ultrapassa nitidamente o bordo posterior dos olhos em vista lateral, chegando ao nível dos ocelos, o que não ocorre em T. guazu, pois não alcança o bordo ocular posterior; pelas distintas esculturas do tegumento do pronoto; pela ausência de depressão longitudinal abdominal ventral no centro da área convexa; pelas diferenças nas estruturas fálicas (Figs. 5-10, Tabela). Forma do falosoma (Ph) ovóide com projeção acuminada, vesica (V) fracamente quitinizada e processo do endosoma com ápice acuminado com numerosos dentículos voltados para baixo. Macroscopicamente a diferenciação é mais simples através da coloração. Em T. guazu a coloração geral é negra com marcas amareladas enquanto que $T$. jurbergi apresenta uma coloração avermelhada forte resultante da conjugação de sua cor castanha com áreas vermelhas e amareladas.

Triatoma oliveirai (Neiva, Pinto \& Lent, 1939) pertence ao mesmo grupo mas é muito diferente pelo tamanho menor dos olhos, os hemiélitros muito curtos que apenas cobrem o 60 urotergito e a cor das manchas claras do conexivo e dos hemiélitros, amarelo pálido.

Etimologia: esta espécie é dedicada ao Dr. José Jurberg, pesquisador do Instituto Oswaldo Cruz, que desde 1960 se dedica ao estudo dos insetos, principalmente dos triatomíneos, vetores da doença de Chagas, dos quais publicou mais de cem trabalhos científicos sobre morfologia comparada, biologia e taxonomia.

\section{AGRADECIMENTOS}

À equipe da FNS - Coordenadoria Regional do Mato Grosso, em especial ao Dr. André Avelino de Siqueira Filho, a Sônia Vieira Camargo da Silva e a Maria Auxiliadora de Moura pelo envio dos espécimes, base da colônia que estudamos.

\section{REFERÊNCIAS}

Aldana E, Lizano E, Ramón F, Valderrama A 1996. Nueva especie de Psammolestes Bergroth de la región SurOccidental de Venezuela (Hemiptera: Reduviidae: Triatominae). Caribbean J Sci 32: 145-149. 
Carcavallo RU, Galíndez Girón I, Jurberg J, Galvão C, Lent H 1997. Pictorial keys for tribes, genera and species of the subfamily Triatominae. Chaves gráficas para as tribos, gêneros e espécies da subfamília Triatominae, p.107-244. In RU Carcavallo, I Galíndez Girón, J Jurberg, H Lent (eds), Atlas of Chagas' Disease Vectors in the Americas. Atlas dos Vetores da Doença de Chagas nas Américas, Editora Fiocruz, Rio de Janeiro.

Carcavallo RU, Martínez A 1987. Comentários sobre Triatoma gallardoi Carpintero, 1986. Chagas 4: 2.

Carpintero DJ 1986. Aporte al conocimiento de los Triatominos en la Argentina. Segunda Comunicación. Ver Mus Arg C Nat "Bernardino Rivadavia" 4: 113-127.

Carpintero DJ, Leguizamón MN 1994. Triatoma funerea, nueva especie de Triatominae. CM Publ Méd 7: 111121.

Del Ponte E 1929. Algunas especies nuevas del gen. Triatoma Lap. Bol Soc Entomol Argentina 1: 3-8.

Fernández-Loayza R 1989. Triatoma matsunoi nueva especie del norte Peruano (Hemiptera, Reduviidae: Triatominae). Rev Per Entomol 31: 21-24.

Galíndez Girón I, Carcavallo RU, Jurberg J, Galvão C, Lent H, Barata JMS 1997a. External morphology and anatomy. Morfologia e anatomia externa, p. 5383. In RU Carcavallo, I Galíndez Girón, J Jurberg, $\mathrm{H}$ Lent (eds), Atlas of Chagas' Disease Vectors in the Americas. Atlas dos Vetores da Doença de Chagas nas Américas, Editora Fiocruz, Rio de Janeiro

Galíndez-Girón I, Carcavallo RU, Jurberg J, Lent H, Barth OM 1997b. Estudo morfológico de Triatoma guazu Lent \& Wygodzinsky, 1979 (Hemiptera, Reduviidae, Triatominae). Mem Inst Oswaldo Cruz 92: 539-543.

Jurberg J, Galvão C 1997. Hermanlentia n. gen. da Tribo Triatomini, com um rol de espécies de Triatominae (Hemiptera, Reduviidae). Mem Inst Oswaldo Cruz. 92: 181-185.

Jurberg J, Lent H, Galvão C 1997. The male genitalia and its importance in taxonomy. Genitálias dos machos e sua importância na taxonomia, p. 85-106. In RU Carcavallo, I Galíndez Girón, J Jurberg , H Lent (eds), Atlas of Chagas' Disease Vectors in the Americas. Atlas dos Vetores da Doença de Chagas nas Américas, Editora Fiocruz, Rio de Janeiro
Lent H 1997. Novos sinônimos de duas espécies de Triatominae da Venezuela (Hemiptera, Reduviidae). Entomol Vect 4: 67-70.

Lent H, Wygodzinsky P 1979. Revision of Triatominae (Hemiptera, Reduviidae), and their significance as vectors of Chagas' disease. Bull Am Mus Nat Hist 163: $123-520$.

Lent H, Jurberg J, Galvão C 1994. Revalidação do gênero Mepraia Mazza, Gajardo \& Jorg, 1940 (Hemiptera, Reduviidae, Triatominae). Mem Inst Oswaldo Cruz 89: 347-352.

Lent H, Jurberg J, Galvão C 1995. Um sinônimo para Triatoma melanosoma Martinez, Olmedo \& Carcavallo, 1987 (Hemiptera, Reduviidae). Entomol Vect 2: 81-82.

Lent H, Jurberg J, Galvão C 1996. Descrição do alótipo (macho) de Triatoma guazu Lent \& Wygodzinsky, 1979 proveniente do Estado do Mato Grosso, Brasil (Hemiptera, Reduviidae). Mem Inst Oswaldo Cruz 91: 313-315.

Martinez A, Olmedo RA, Carcavallo RU 1987. Una nueva subespecie Argentina de Triatoma infestans. Chagas 4: 7-8

Mazza S, Gajardo TR, Jorg ME 1940. Mepraia novum genus de Triatomidae. Mepraia spinolai (Porter, 1933), nov. comb., redescripción de macho y descripción de hembra. Mis Est Pat Reg Arg 44: 3-30.

Pinto CF 1926. Triatomídeos da Venezuela, com a descripção de uma nova espécie do gênero Eutriatoma (Eutriatoma arthuri n.sp.). Ann Fac Med São Paulo 1: 83-87.

Porter CE 1934. Una Triatoma nueva Chilena. Rev Chilena Hist Nat Pura Aplic 37: 192-193.

Serra OP, Serra RG, Von Atzingen NCB 1980. Nova espécie do gênero Rhodnius da Amazônia, Estado do Pará, Brasil. (Hemiptera,Triatominae), p. 120. Anais do V Congresso Brasileiro de Parasitologia, Rio de Janeiro, RJ, Brasil.

Valderrama A, Lizano E, Cabello D, Valera M 1996. Panstrongylus turpiali, n.sp. (Hemiptera: Reduviidae: Triatominae) from Venezuela. Caribbean J Sci 32: 142-144.

Valente VC, Valente SAS, Siqueira-Filho JA, Camargo SV, Moura MA 1997. I - Epidemiologia do Triatoma guazu em Barra do Garça, Mato Grosso, Brasil: Resultados preliminares, p. 91. Anais do XV Congresso Brasileiro de Parasitologia, Salvador, BA, Brasil. 